\title{
Desempenho escolar de meninos e meninas: há diferença?
}

\author{
Boys and girls' performances at school: \\ is there any difference?
}

Maria Cláudia Dal'Igna ${ }^{1}$

\section{RESUMO}

Este artigo desdobra-se de uma pesquisa desenvolvida desde a perspectiva dos estudos de gênero e dos estudos culturais, articulados com o pósestruturalismo de Michel Foucault. $\mathrm{Na}$ articulação desses campos, analiso alguns dos modos pelos quais o gênero atravessa (é incorporado e mobilizado) e constitui o discurso pedagógico que, articulado com outros discursos, define e regula o que se entende por desempenho escolar nos anos iniciais de escolarização. Para compor meu corpus de pesquisa, construí uma metodologia de investigação, que intitulei de Grupo de discussão, com professoras de séries iniciais das redes municipal e estadual de ensino da cidade de São Leopoldo/RS. A trama das ferramentas conceituais com os materiais possibilita-me tanto visibilizar quanto discutir, analisar e problematizar as relações de poder que constituem, classificam e posicionam meninos e meninas em lugares diferenciados e hierarquizados no que se refere ao desempenho escolar, atribuindo a este diferentes significados.

Palavras-chave: Educação escolar; Estudos de gênero; Desempenho escolar.

\footnotetext{
${ }^{1}$ Doutoranda em Educação da Universidade Federal do Rio Grande do Sul (UFRGS). Professora da Rede Municipal de Ensino de Porto Alegre/RS e da Universidade do Vale do Rio dos Sinos (UNISINOS/RS). Membro do Grupo de Estudos de Educação e Relações de Gênero (GEERGE/UFRGS) e do Grupo de Estudo e Pesquisa em Inclusão (GEPI/UNISINOS). mcdaligna@hotmail.com.
} 


\section{ABSTRACT}

This article has stemmed from a research developed from the perspective of gender and cultural studies, linked to Michel Foucault's post-structuralism. By connecting those fields, I have analyzed some of the ways gender has crossed (embodied and mobilized) and constituted the pedagogical discourse which, associated with other discourses, has defined and regulated what has been understood as school performance in the first grades. In order to compose the research corpus, I have built an investigation methodology, which I have called Group of Discussion, with teachers of initial grades from both municipal and state schools in São Leopoldo/RS. The intertwining of conceptual tools and materials has enabled me to visualize, as well as discuss, analyze, and problematize the power relationships that have constituted, classified, and ranked boys and girls in differentiated, hierarchical places concerning school performance, thus assigning different meanings to it.

Keywords: School education; Gender studies; School performance.

\section{EM FOCO:}

\section{DESEMPENHO ESCOLAR DE MENINOS E MENINAS}

A lente da máquina fotográfica captura a imagem. Do lado esquerdo, um grupo. Do lado direito, outro grupo. Ambos os grupos estão uniformizados. Cada grupo aparece disposto do mesmo modo: parte dos componentes está sentada, a outra parte está em pé, disposta atrás da fileira de cadeiras. Sua disposição simula uma daquelas fotos de equipe de futebol, daquelas que são capturadas em competições. Essa descrição poderia referir-se a dois times de futebol, mas alguns detalhes tiram a dúvida. Trata-se de dois grupos: meninos e meninas. Dois grupos uniformizados - uniforme de escola. Atrás do grupo, a imagem de um quadro branco identifica o local onde foram fotografados: uma sala de aula. Então, não se trata apenas de meninos e meninas, mas de alunos e alunas. A idéia de equipe, de competição não é sugerida em vão. A 
reportagem que sucede a foto anuncia resultados. Discute a questão do desempenho. Desempenho escolar de meninos e meninas ou, ainda, desempenho das meninas versus desempenho dos meninos. O título da matéria também sugere uma comparação: "Existe outra diferença". Outra diferença entre homens e mulheres, meninos e meninas, alunos e alunas. Uma diferença que se refere ao desempenho escolar (Zakabi, 2004).

Neste texto, não tomo a reportagem como foco de análise. Ao contrário, pretendo utilizá-la para argumentar que o desempenho escolar de meninos e meninas tem sido alvo de discussão em diferentes instâncias e analisado sob as mais diversas perspectivas. Como mulher, professora e pesquisadora, interessa-me discutir e analisar o desempenho escolar do ponto de vista dos estudos de gênero. Tal exercício pretende contribuir para a discussão e análise da constituição de masculinidades e feminilidades no espaço escolar. ${ }^{2}$

Para desenvolver meus argumentos, utilizo-me de um conjunto de análises empreendidas no contexto de minha pesquisa de dissertação de mestrado (Dal'igna, 2005a), ${ }^{3}$ desenvolvida desde a perspectiva dos Estudos de Gênero e dos Estudos Culturais, articulados com o pós-estruturalismo de Michel Foucault. ${ }^{4} \mathrm{Na}$ articulação desses campos, analisei alguns dos modos como o gênero atravessa (é incorporado e mobilizado) e constitui o discurso pedagógico que, articulado com outros discursos, define e regula o que se

\footnotetext{
2 Uma versão deste texto foi publicada sob o título Desempenho escolar e gênero: um estudo com professoras de séries iniciais nos anais da $28^{a}$ Reunião Anual da Associação Nacional de PósGraduação e Pesquisa em Educação (ANPED), realizada em Caxambu/MG, em outubro de 2005. Para maior detalhamento, ver Dal'Igna (2005b).

3 Essa pesquisa foi desenvolvida sob orientação da Profa. Dra. Dagmar Estermann Meyer, no âmbito da Linha de Pesquisa Educação, Sexualidade e Relações de Gênero da UFRGS, e contou com o apoio financeiro da Coordenação de Aperfeiçoamento de Pessoal de Nível Superior (CAPES).

4 Adoto o uso do nome e sobrenome do/a autor/a - quando esse/a é citado/a pela primeira vez no corpo do texto - para visibilizar mulheres e homens a quem me refiro. Tanto a grafia o/a quanto essa opção são políticas e decorrem de minha inserção no campo dos Estudos Feministas.
} 


\section{4}

entende por desempenho escolar nos anos iniciais de escolarização. Para compor meu corpus de pesquisa, construí uma metodologia de investigação, que intitulei de Grupo de discussão, com professoras de séries iniciais das redes municipal e estadual de ensino da cidade de São Leopoldo/RS. ${ }^{5}$

A trama das ferramentas conceituais com os materiais possibilitou-me argumentar que a definição da noção de desempenho escolar está relacionada com a instauração de um conjunto de normatividades que permitem às professoras participantes da pesquisa $(\mathrm{PPs})^{6}$ avaliar todos e todas - comparar, diferenciar, classificar -, regulando e conformando aquilo que entendemos por desempenho escolar normativo. O movimento de exame do conteúdo da noção de desempenho escolar permitiu-me também analisar como o gênero atravessa e dimensiona esse conteúdo. Passo agora a explorar as análises realizadas sobre essa questão.

\section{"Não vejo diferença nenhuma":}

\section{a produção de diferenças e desigualdades de gênero}

Tendo em vista as normas de conhecimento e de comportamento acionadas para avaliar os desempenhos, é possível afirmar que o processo de diferenciação dos desempenhos ficava menos visível quando as PPs recorriam às normas de conhecimento em suas falas. Quando perguntadas sobre as diferenças de desempenho escolar no que se refere ao conhecimento, as PPs argumentavam sobre a não-existência dessas diferenças ou, ainda, sobre a impossibilidade de constatá-las. ${ }^{7}$

5 As discussões de cada encontro foram gravadas e transcritas. Todos os procedimentos foram previamente contratados e autorizados, por escrito, por todas as professoras participantes.

6 Adoto o uso da sigla PPs para fazer referência às Professoras Participantes da pesquisa.

7 As falas são diferenciadas das citações pela sua inserção em quadros. Em alguns momentos, recorro a trechos das falas, inserindo-os no corpo do texto, identificados por aspas duplas As supressões de trechos de fala são indicadas pelos colchetes. Por fim, esclareço que todos os nomes citados (das PPs, dos alunos e das alunas) são fictícios. 
MC - [Retomo a questão do conhecimento vista nos encontros anteriores.] Com isso que vocês estão trazendo, da leitura, da concentração, da capacidade verbal, seria possível pensar que existem diferenças nas dificuldades apresentadas pelos meninos e pelas meninas?

Beatriz - [...] Nas turmas que eu tenho, e acho que também nas outras, não dá para dizer... porque as diferenças sociais também são muitas. Então, não dá para fazer um diagnóstico tão exato assim. Pelo menos eu não consigo fazer. [...] Porque a gente trabalha com conhecimentos básicos e iguais... Porque a gente trata eles igual, como foi dito ali, então, a gente não faz um trabalho objetivando descobrir essas diferenças. [...]

Deise - Eu também não consigo, assim... fazer essa diferença, essas características bem distintas de um sexo ou outro.

Encontro V - 21 de junho de 2004.

Beatriz - A questão do conhecimento. O que se trabalha, no caso, é como também está dito no documentário, a gente trabalha com conhecimentos iguais, porque a gente tem uma turma, a gente não vai fazer atividades diferenciadas para os meninos e para as meninas, não é...

MC - Essa é uma questão interessante...

Sílvia - Ah, é...

Beatriz - ... a gente não faz. Por quê? O que existe? Existe um plano de curso, as exigências de que o professor tem que dar contar, fazer as crianças saberem aquilo, então, tu trabalha igual. [...]

Encontro V - 21 de junho de 2004.

As falas são indicativas de que as PPs justificam sua dificuldade em referir as diferenças de desempenho entre meninos e meninas de muitas formas. Uma delas está relacionada com noções de neutralidade e imparcialidade, mobilizadas para definir suas práticas. As atividades são as mesmas, os conhecimentos exigidos são os mesmos para meninos e meninas - leitura, escrita, noções de matemática -, um conhecimento naturalizado como desde sempre "lá", no plano de curso. E aqui é 
interessante pensar como a justificativa de neutralidade e imparcialidade da prática pedagógica aparece associada à norma de conhecimento. Entendo que essa norma de conhecimento é definida no interior de discursos da psicologia do desenvolvimento e da psicogênese da língua escrita - uma norma de conhecimento fundada na noção de criança em desenvolvimento, em elementos supostamente intemporais e universais que lhe garantem status científico. Quando as PPs referem que os conhecimentos são os mesmos para meninos e meninas, organizados a partir de regras supostamente democráticas, porque universais e aplicáveis a todos/as, estão operando com uma noção de conhecimento e de desenvolvimento como algo natural, o que contribui para que reconheçam suas práticas como práticas de mediação, como espaços de desenvolvimento, e não questionem seu caráter de produção (Larrosa, 2000), principalmente no que se refere à produção de diferenças e desigualdades de gênero. ${ }^{8}$

Assim, instaura-se uma norma - criança natural, desprovida de gênero e sexualidade. Vejamos a discussão abaixo:

\footnotetext{
MC - Por um lado, tem a questão de que a escola trata todo mundo da mesma forma. De outro, tem as diferenças, e vocês procuram considerá-las. Então, como é que fica isso para vocês? O que vocês acham?

[...]

Deise - Os pequenos, assim... Eu trabalho com os pequenos, 7,8 anos ( $1^{\text {a }}$ série), então, para eles, tudo está bom. Não noto tanto essa questão: ah, é de menino, é de menina.

$[\ldots]$

Deise - Diferenças para avaliar os meninos ou as meninas?
}

8 Para uma discussão detalhada sobre alguns dos significados que têm sido atribuídos ao conhecimento escolar no contexto da escola e suas implicações na produção de diferenças e desigualdades, ver Dal'Igna (2007a). 
MC - É. Se isso aparece, se as diferenças são consideradas especificamente na hora da avaliação, na hora de uma determinada atividade ou na hora de organizar alguma coisa... se isso aparece assim? [Muitas respondem: ? Não.]

Deise - Eu também não [...] não, assim, relacionado a gênero. [...]

Liane - Eu também acho. A gente pede avaliação, como ela colocou, é o que a gente costuma fazer.

$[\ldots]$

Marta - [...] Não vejo diferença nenhuma.

Deise - É, eu também não.

Encontro VI - 28 de junho de 2004.

MC - E tem alguma diferença em relação a meninos e meninas, assim, que tu nota?

Deise - Ah, assim, eu não consigo notar. Até eu não sei se, em função de eu trabalhar sempre com pequenos, que isso não se salienta muito. [...].

Encontro VI - 28 de junho de 2004.

É interessante observar como as PPs mobilizam, tanto nos excertos acima quanto em outros momentos, a noção de criança assexuada ou, ainda, a figura desta associada com pureza e ingenuidade. Valerie Walkerdine (1999a), discutindo as implicações da cultura popular no processo de erotização das meninas, argumenta que a criança erotizada representa uma ameaça para a criança natural, produto da psicologia e de seus discursos sobre a infância natural. Como explica a autora, essa noção de infância, cujo modelo de racionalidade se desenvolve naturalmente, concorre para reforçar a idéia de um estado inocente e imaculado, portanto, para entender a infância como neutra em termos de gênero e sexualidade.

Nesse contexto discursivo, para justificar a neutralidade e imparcialidade do processo de definição do desempenho escolar de meninos e meninas, as PPs mobilizam tanto uma norma de conhecimento quanto uma norma de desenvolvimento infantil que descreve a criança 
"pequena" associada com pureza e ingenuidade e como neutra em termos de gênero e sexualidade. $\mathrm{Na}$ medida em que as normas não são problematizadas, elas funcionam para produzir e reiterar noções de masculinidade e feminilidade. Talvez essa seja mais uma pista importante quanto à invisibilidade das discussões sobre relações de gênero no âmbito da escola, principalmente no que se refere às séries iniciais do ensino fundamental.

Considerando que as identidades femininas e masculinas são produto de processos educativos que envolvem estratégias sutis, refinadas e naturalizadas (Meyer, 2003), torna-se importante examinar em que medida a escola está implicada com a produção de diferentes e conflitantes modos de conceber e de viver o gênero e a sexualidade, modos que definem, entre outras coisas, aquilo que entendemos por desempenho escolar. Caberia, então, perguntar, por exemplo, até que ponto as normas de conhecimento e de comportamento vigentes no espaço escolar estão implicadas com a produção das diferenças e desigualdades de gênero. Tomando essa questão, é possível argumentar que as PPs atribuem diferentes significados aos desempenhos de meninos e meninas, o que se pode discutir melhor a partir dos excertos a seguir.

MC - [...] Pensando agora nas diferenças de meninos e meninas nas fichas de encaminhamento para as aulas de reforço. [...] Há diferença nos encaminhamentos de meninos e meninas para as aulas de reforço? Quais?

Marta - Na minha prática como professora de recuperação do ano anterior, os adjetivos: meninos - desatento, inseguro, desinteressado, distraído, preguiçoso, relaxado... e, para as meninas, raramente aparecia um adjetivo desses.

Nádia - Só dificuldade mesmo.

Marta - Ahã. Ela tem dificuldade na matemática, em fazer cálculos [...], e os meninos não. Ele tem dificuldade devido à desatenção, só conversa em 
aula, só quer brincar...

Nádia - ... não demonstra tanto interesse.

Encontro IV - 14 de junho de 2004.

MC - Sobre os conteúdos, conhecimentos, vocês percebem alguma diferença de dificuldade, de domínio de alguns conteúdos? Quando referimos dificuldades de meninos e meninas, quais conteúdos?

[Silêncio. Retomo a pergunta.]

Nádia - Na minha turma, tem 16 meninos e 14 meninas, e tenho mais meninos com dificuldades do que meninas.

MC - Em relação ao conhecimento? Qual? Alfabetização?

Nádia - É. Mas devido a quê? À distração, se distraem muito fácil, em vez de estarem trabalhando, eles prestam atenção...

Liane - Eu queria também... São muito mais meninos [com dificuldades] do que meninas. Eu até queria destacar o caso da biblioteca. [...] Todos, em geral... Leitura e interpretação de texto, eles escrevem muito errado.

Nádia - ... mas é porque mal bateu, e eles já querem uma bola... Tem que ver um outro horário para a biblioteca...

Liane - Eu já liberei outro horário, eles não têm interesse... [...].

Encontro IV - 14 de junho de 2004.

Nos excertos acima, de modo mais explícito, é possível identificar as implicações da linguagem na instituição e demarcação de diferentes posições para os gêneros. Esses diferentes modos de descrever os desempenhos têm efeitos. Mecanismos de naturalização, essencialização e dicotomização são acionados e funcionam para justificar as diferenças de desempenho entre meninos e meninas, tanto no que se refere a comportamentos quanto no que diz respeito a conhecimentos. 
Em relação ao conhecimento, meninos e meninas estão abaixo da média - são desvios -, mas seus desempenhos são classificados e hierarquizados de diferentes formas. Os meninos não atingiram a média devido ao seu comportamento - desatento, inseguro, desinteressado, distraído. Quanto às meninas, suas dificuldades são justificadas por sua (in)capacidade cognitiva, portanto, não atingiram a média por sua falta de conhecimento.

No que diz respeito a uma das implicações do conceito de gênero mais especificamente aquela que se refere ao seu caráter relacional -, poderíamos argumentar que os mesmos discursos que permitem que as meninas sejam narradas e posicionadas como carentes de um tipo de raciocínio considerado correto possibilitam que os meninos sejam apresentados e descritos como dotados, por natureza, desse modo de raciocinar. A capacidade intelectual dos meninos não é colocada em questão, uma vez que seu insucesso é justificado de outras formas. ${ }^{9}$

Nessa direção, o uso do conceito de gênero permite também questionar a neutralidade e universalidade atribuída à norma de conhecimento, pois essa maneira de justificar as diferenças de rendimento entre meninos e meninas contribui para naturalizar algumas habilidades cognitivas como masculinas e outras como femininas. No caso das meninas, estas apresentariam mais dificuldades em campos do conhecimento caracterizados pelo predomínio do pensamento abstrato.

Concordo com Walkerdine (1999b) quando argumenta que as teorias da razão e do raciocínio na educação matemática que ensinam um modo de significar o desenvolvimento e o desempenho tornam-se verdades inquestionáveis. Ainda sobre essa questão, Marisa Costa (2001, p. 59) diz que "o campo supostamente neutro das equações, contas e

\footnotetext{
9 Sobre essa questão, sugiro o livro Failing Boys?: Issues in gender and achievement, organizado por Debbie Epstein (1998).
} 
números constitui uma arena onde a própria capacidade de pensar é questionada e posicionada estrategicamente para fortalecer histórias e identidades". No contexto desta pesquisa, os fragmentos discursivos contribuem para produzir, atualizar e reiterar noções muito particulares de gênero. Além disso, funcionam para legitimar uma forma correta de conhecer que pressupõe um tipo de racionalidade, uma progressão rumo ao pensamento formal-abstrato, considerado o grau de desenvolvimento normal do sujeito-adulto masculino (Walkerdine, 1999b).

Essa forma de justificar o baixo desempenho das meninas contribui ainda para que elas sejam posicionadas numa hierarquia apropriada do intelecto. Desse modo, pode-se afirmar que possuir ou não potencial pode ser mais importante do que apresentar um bom rendimento. $\mathrm{Na}$ medida em que tanto a noção de potencial quanto a noção de desempenho são generificadas, é possível pensar que o desempenho em sala de aula pode não ser indicativo do potencial verdadeiro; no entanto, esse argumento só parece funcionar no que diz respeito ao desempenho dos meninos (Cohen, 1998; walkerdine, 1995).

A fim de explorar um pouco mais essa questão, pode-se argumentar também que os mecanismos de naturalização, essencialização e dicotomização da masculinidade e da feminilidade são acionados e funcionam ainda de outros modos. Na medida em que as PPs descrevem suas práticas como neutras e imparciais, elas invocam a existência de diferenças biológicas naturais, próprias de cada gênero, para justificar as diferenças de desempenho escolar entre meninos e meninas. Vejamos as seguintes falas, produzidas no contexto da discussão desencadeada pelo

\footnotetext{
10 No quinto encontro, exibi o documentário intitulado Aprendendo com a diferença: por que os homens não passam a ferro, o qual apresenta um conjunto de estudos científicos sobre as diferenças de funcionamento dos cérebros masculino e feminino para justificar as diferenças de desempenho entre meninos e meninas. Esse documentário foi exibido no Canal 41 (GNT) da Globosat (TV a cabo). Para maiores detalhes, ver homepage: <http://globosat.globo.com/gnt/>.
} 
documentário $^{10}$ assistido com as PPs no quinto encontro. A elas, foi solicitado destacar e comentar aspectos que mais chamaram a sua atenção.

Beatriz - Não é que chamou mais atenção, mas o que mais ou menos confere com o que a gente observa na escola é a questão da agitação, da agressividade, que é uma questão funcional, da parte biológica mesmo, e que a gente comprova realmente. A gente observa esse tipo de coisa, se bem que, claro que tem as meninas agressivas e também tem os meninos mais calmos, mas...

MC - Que mais gente que vocês gostariam de destacar?

Sílvia - A coisa da atenção, diferença de atenção. $O$ tempo de concentração de meninos e meninas, isso também a gente observa, falando em termos de sala de aula. Realmente as meninas se concentram bem mais. Por exemplo, na série de alfabetização, onde se costuma ter os livrinhos para ler depois das atividades, as meninas pegam e lêem o livrinho, os meninos não. Eles mal abrem, olham e já querem outros, eles não se concentram num...

Deise - É, isso é verdade...

Sílvia - ... E as meninas, não, mesmo aquelas que têm dificuldade na leitura, elas tentam, elas se demoram com o livro. Então, eles acabam perturbando, porque eles já querem trocar de livrinho [...]. Eles não têm aquela concentração. Eu noto bastante isso na minha turma...

Beatriz - É a questão da habilidade verbal, não é... Sílvia - É.

Encontro V - 21 de junho de 2004.

Luciana - Eu não sei. Tentando pensar sobre isso... É um tipo de inteligência ou um tipo de capacidade? Porque as meninas, a gente observa assim: se for trabalhar com elas o traçado das letras, por exemplo, o som, elas se atêm mais a isso, detalhes, percepção, observação, estabelecer relações, são várias habilidades que entram que podem estar ligadas a um tipo de quê? De inteligência. A um tipo de desenvolvimento do cérebro. $\mathrm{O}$ hemisfério esquerdo e direito se harmonizam de forma melhor... não sei. Já os 
meninos... Coloca os meninos para montar um carro, pede para eles montarem qualquer... Estragou um negócio na escola, mas eles estão prontos: "me dá a chave de fenda que eu quero", mesmo os pequeninhos da pré-escola. [...] Então, é um outro tipo de campo, e a nossa educação é uma coisa repetitiva, é uma coisa exaurida, de copiar, de reproduzir, de ficar sentadinho, de ficar quietinho. Tem que haver alguma coisa no meio disso aí...

MC - Que mais?

Sílvia - São habilidades...

Beatriz - São habilidades, como apareceu no documentário. As habilidades dos homens são mais práticas, mais de botar a mão na massa, eles gostam mais disso. Então, eles desenvolvem mais essa habilidade, e aí a concentração fica mais difícil para eles...

Encontro V - 21 de junho de 2004.

No contexto discursivo que torna tais falas possíveis, articulam-se fragmentos de discursos da medicina e da biologia que contribuem para significar as diferenças de corpos masculinos e femininos. Um exemplo disso são as explicações acerca do funcionamento cerebral de meninos e meninas. Algumas pesquisas, como a do psicólogo e terapeuta familiar inglês Steve Biddulph, autor de um livro traduzido para o português com o título de Criando meninos, ${ }^{11}$ vêm argumentando que certas diferenças entre meninos e meninas podem ser explicadas pela biologia. Biddulph (2002) cita duas das maiores diferenças que "influem" sobre a aprendizagem e o desenvolvimento: a) os efeitos dos hormônios masculinos, mais especificamente, a testosterona, no comportamento e desenvolvimento dos meninos; b) o formato e configuração do cérebro de meninos e meninas, que se desenvolve de maneiras diferentes, afetando seus modos de pensar e agir. Desse modo, Biddulph (2002) explica, por

11 Título original: Raising Boys: why boys are different. 
exemplo, que é preciso saber que a produção de testosterona afeta o comportamento de meninos; esse saber nos ajudaria a responder perguntas como estas: por que eles têm um comportamento mais agitado e competitivo? Por que eles se interessam por brincadeiras movimentadas? Por que seu rendimento é melhor nas ciências lógicomatemáticas? Ou: por que as dificuldades de aprendizagem, autismo e outras disfunções atingem os meninos em maior número?

Essas maneiras de justificar as diferenças de desempenho também estão implicadas com a produção de hierarquias de gênero (Meyer, 1996). Nesse sentido, há alguns pontos aqui que podem ser analisados.

Articulando gênero e poder, poderíamos problematizar esses e outros discursos sobre as diferenças biológicas que têm significado e organizado o contexto social, de modo mais amplo, como também o contexto escolar. As diferenças biológicas parecem contribuir para reiterar e legitimar a superioridade masculina e a inferioridade feminina no que se refere ao desempenho escolar. $O$ fracasso ou baixo rendimento dos meninos permanece sendo explicado por seu comportamento, uma vez que eles são naturalmente dotados de uma agitação que não conseguem controlar. Já o bom desempenho das meninas é associado à sua feminilidade passiva. ${ }^{12}$

Para discutir e analisar essa questão, vale a pena recordar a afirmação de Joan Scott (1995) acerca do gênero como primeiro modo de dar significado às relações de poder. No contexto social, é onde primeiro a essencialização das diferenças masculinas e femininas, baseadas na diferença sexual, funciona estabelecendo limites e possibilidades. É nesse contexto que Dagmar Meyer (1996), inspirada em Scott, argumenta que o

\footnotetext{
12 Para uma discussão detalhada acerca das normas de comportamento colocadas em funcionamento pelas PPs da pesquisa no processo de avaliação dos desempenhos de meninos e meninas
} 
que se percebe como diferença sexual atravessa e delimita, de algum modo, todas as relações sociais. Muito antes de ingressarem na vida escolar, meninos e meninas já parecem destinados a lugares sociais distintos em função daquilo que a cultura nomeia como diferenças sexuais.

No interior de determinados discursos, como é o caso dos discursos médicos e biológicos, as diferenças sexuais assumem um estatuto de fixidez e universalidade. Tais discursos, acolhidos em uma sociedade, funcionam como verdades, o que torna seu questionamento impensável e antinatural (Foucault, 2003). O status de verdade adquirido por tais discursos posiciona meninos e meninas de modo diferenciado e hierarquizado. Sobre isso, Walkerdine (1999c) argumenta que as "descobertas científicas" estão implicadas na produção e legitimação de posições sociais possíveis, isso porque o status atribuído a elas permite que sejam lidas como afirmações, como fatos.

Há, ainda, duas questões que poderiam ser abordadas. Meyer (2003), analisando uma reportagem publicada em 2003 sobre o aumento dos índices de obesidade, oferece alguns insights importantes sobre o que ali poderia ser analisado. $\mathrm{O}$ que eu gostaria de destacar, a partir desse exemplo, por sua importância para a análise, está relacionado com um dos desdobramentos discutidos pela autora: os modos pelos quais o gênero atravessa e constitui formas científicas de conhecer e, ao mesmo tempo, torna possíveis tais formas de conhecimento.

No contexto desta pesquisa, esse desdobramento permite considerar que pressupostos de masculinidade e feminilidade, ativos no contexto cultural em que vivemos, estão implicados na constituição de "descobertas científicas", como as mobilizadas no documentário apresentado e nas falas das PPs. Isso implica perguntar, por exemplo: em que medida "descobertas" como essas sobre as diferenças cerebrais entre meninos e meninas seriam legitimadas e sancionadas como verdades se, 
em nossa cultura, determinados comportamentos (falta de atenção e concentração, agitação e agressividade) não fossem considerados atributos "inerentemente" masculinos e outros "inerentemente" femininos (docilidade, disciplina, concentração)?

A segunda questão está relacionada com o modo como as PPs articulam algumas das explicações mais recorrentes para justificar os desempenhos de meninos e meninas. O melhor rendimento das meninas é justificado por seu maior interesse, atenção, esforço, enquanto os meninos não aprendem porque têm dificuldades de concentração. Essa explicação para as diferenças de rendimento entre meninos e meninas atribui às meninas - que aprendem desde cedo a ser bem-comportadas, organizadas, disciplinadas, obedientes, caprichosas - uma capacidade maior de adaptação à escola. Já os meninos teriam maior dificuldade de adaptação porque são indisciplinados, agitados, desorganizados, daí seu baixo desempenho escolar. As falas das PPs acionam fragmentos de discursos científicos articulados a noções de senso comum acerca da masculinidade e da feminilidade. Nesse sentido, penso que é importante analisar como determinados enunciados de discursos científicos, ao serem apresentados como descobertas incontestáveis de pesquisas científicas, contribuem para que reconheçamos esses modos de "ser menino" e "ser menina" como parte da natureza de ambos e para que passem a funcionar como enunciados do senso comum (Meyer, 2004).

O não-questionamento das normas de conhecimento, bem como as práticas que tais normas produzem, têm ainda outros efeitos. As diferenças "naturais" apontadas pelas PPs permitem fixar normas de comportamento implicadas com os processos de diferenciação dos desempenhos. Analisando-se os excertos de fala apresentados, pode-se argumentar que aquilo que as PPs definem como bom desempenho escolar está relacionado com uma norma de comportamento e, ainda, com uma noção de feminilidade. Considerando-se que, como refere uma das PPs, "nossa 
educação é uma coisa repetitiva, é uma coisa exaurida, de copiar, de reproduzir, de ficar sentadinho, de ficar quietinho", as meninas, por possuírem essas habilidades, poderiam adaptar-se melhor à escola e, conseqüentemente, apresentariam melhor desempenho. O comportamento indisciplinado dos meninos estaria, assim, prejudicando seu desempenho escolar. Essa poderia ser uma forma de analisar a presença masculina em maior número nas classes de reforço, uma hipótese já apontada em outras investigações (Silva et al. 1999, por exemplo).

Contudo, gênero, quando mobilizado no discurso pedagógico, constrói significados diferenciados que permitem classificar comportamentos como masculinos e femininos, o que possibilita hierarquizar tais comportamentos, atribuindo-lhes diferentes valores. Isso pode ser observado no mesmo excerto, que poderia indicar uma outra alternativa de significação do desempenho escolar de meninos e meninas. Se, por um lado, há uma qualificação positiva do desempenho escolar das meninas quando este é associado com sua capacidade de adaptação escolar, por outro lado, há também sua desqualificação. Os verbos "repetir, exaurir, copiar, reproduzir" desqualificam o trabalho escolar. Além disso, os diminutivos "sentadinho" e "quietinho" também são sugestivos dos valores agregados a tais comportamentos.

As mesmas falas podem sugerir que a noção de bom desempenho não pode ser discutida e analisada considerando-se noções homogêneas, essenciais e universais de masculinidade ativa e feminilidade passiva. As falas possibilitam problematizar a estabilidade e fixidez da feminilidade passiva para tornar visíveis operações de poder que instituem e legitimam essa noção de feminilidade. Considerando que o processo de fixação de uma identidade como norma pressupõe processos de comparação e individualização constantes, argumento que os processos de diferenciação possibilitam também fragmentar e pluralizar a noção de feminilidade passiva. Além disso, é importante considerar que os sujeitos resistem à 
norma - reagem, recusam, respondem -, não estão assujeitados

efetivamente e se atualizam nesse movimento permanente de relações de força.

Observemos os quadros abaixo:

MC - Comportamento...

Nádia - É.

$\mathrm{MC}-\mathrm{Uhu} . .$.

Deise - Eu trabalho constantemente isso. Isso prejudica. Nossa! Uma criança, assim, que não tem parada! Até hoje, a gente estava discutindo - a gente também teve conselho de classe hoje -, acaba prejudicando. Ela poderia estar além daquilo, mas em função da agitação... e tanto assim... É, menina, minha turma este ano é bem agitada... é meninos e meninas [ênfase na afirmação], geralmente os rotulados são os meninos, mas não é bem assim, não. Essa minha realidade este ano já muda um pouquinho isso... é bem geral, assim.

[...]

Marta - É. Eu tinha uma turma... Eu tinha 20 meninas e 10 meninos. Eu pensei assim: "não, vai ser tudo tranqüilo" [risos]. [...] Eu acho que o que muda um pouco é a diferença de atividades. Os meninos, eles tendem a ter um tipo de agitação, e as meninas, outro. [...]

Deise - É, com certeza...

Marta - Antigamente, a gente dizia assim: "ah, as meninas são mais estudiosas que os meninos...”. Já não se pode constatar isso com certeza.

Deise - ... Os cadernos de bichinhos, enfeitadinhos. E hoje em dia não tem nada disso. Tem de tudo um pouco, não é?

Encontro I - 24 de maio de 2004.

Beatriz - Referindo-se às turmas com que ela trabalha: $1^{\mathrm{a}}$ e $4^{\mathrm{a}}$ série]. [...] Ali não tem tanto assim, como é que eu vou dizer, não tem muito parâmetro de mais meninos ou mais meninas, entendeu? É mais ou menos igual a coisa. Dependendo do número de alunos que tem nas turmas, no caso, eu tenho uma turma de 30 alunos, tenho 20 meninas e 
10 meninos. Exatamente o dobro de meninas. E elas são tão conversadeiras quanto os meninos! Sabe, tão, assim, agitadas... E tem umas que têm uma goela que eu vou te contar! Às vezes, várias vezes, eu tenho que parar, pedir licença para elas para poder continuar a minha explicação ou eu tenho que parar uma explicação porque elas estão conversando junto comigo. [...] Por exemplo, no ano passado, eu trabalhava com $2^{\text {a }}$ série e eu tinha as meninas mais agitadas. Então, as meninas eram assim de se grudar pelos cabelos, sabe, dentro da sala de aula.

Daniela - Eu acho que hoje em dia está bem parelha a coisa. Não dá para dizer que as meninas estão menos que os meninos... como era antigamente, elas vinham bonitinhas. Eu sou meio suspeita porque, como tu falou, o aluno que não tem limites... Eu nunca tive problemas com alunos que não têm limites porque, não sei se por que eu gosto... O aluno, para mim, quanto menos limite ele tem, mais ele te exige, mais ele quer. É porque ele está além daquilo ali. Aquilo ali está [...] muito chato. [...]

Encontro III - 7 de junho de 2004.

MC - [...] Pensando agora nas diferenças de meninos e meninas nas fichas de encaminhamento para as aulas de reforço. [...] Há diferença nos encaminhamentos de meninos e meninas para as aulas de reforço? Quais?

[...]

Nádia - As fofoquinhas...

Marta - As fofoquinhas... tem [nos pareceres das] meninas. Com certeza!

Encontro IV - 14 de junho de 2004.

Convivendo de modo conflitante com a feminilidade passiva, está uma noção de feminilidade ativa, definida no interior da noção de feminilidade e também na relação com a masculinidade ativa. Tais possibilidades de análise estão relacionadas com dois desdobramentos do conceito de gênero: a noção de que feminino e masculino se constroem em 
relação e de que tais noções não são homogêneas. Esses desdobramentos permitem explorar a pluralidade e a conflitualidade presentes tanto nos processos de diferenciação que fixam determinados modos de viver os gêneros quanto no processo de normatização dos desempenhos.

Em primeiro lugar, um mesmo adjetivo é utilizado para descrever o comportamento de meninos e meninas: "agitado". Isso contribui para reiterar a implicação da norma de comportamento no processo de significação do desempenho escolar. No entanto, como alertam as PPs, "os meninos, eles tendem a ter um tipo de agitação, e as meninas, outro", o que possibilita pensar que há diferenças nos comportamentos de meninos e meninas. A agitação das meninas é caracterizada pelas conversas em alto tom de voz ("tem umas que têm uma goela que eu vou te contar!"), brigas e fofocas. Esse modo de descrever o comportamento das meninas contribui para fragmentar a noção de feminilidade - há meninas que são obedientes, passivas e conformadas às regras, portanto, bem-comportadas, assim como há meninas agitadas, que desafiam as regras (estas seriam malcomportadas?). Em segundo lugar, pode-se argumentar que o adjetivo produz, atualiza e repete pressupostos de feminilidade que fixam determinados atributos como essencialmente femininos, quais sejam: as mulheres fofocam, gritam, brigam agarrandose pelos cabelos. Ou seja, expressa-se um paradoxo que, ao mesmo tempo, reitera e contesta o pressuposto da existência de uma natureza feminina (não necessariamente passiva - brigar e puxar-se pelos cabelos não sugerem passividade).

Existe, ainda, um outro ponto que merece ser explorado. $\mathrm{O}$ processo de diferenciação mobilizado nas falas das PPs funciona para multiplicar as formas de ser menina e de viver essa feminilidade, assim como para classificá-las. Trata-se de atribuir um valor para cada comportamento - de posicionar uma feminilidade como desqualificada do ponto de vista do comportamento considerado "adequado" para as 
meninas, tanto num contexto social mais amplo quanto no espaço escolar. Assim, ainda que fofocar seja considerado um atributo feminino, não é um comportamento desejável.

A fofoca como atributo feminino também é discutida e analisada na tese de Ruth Sabat (2003) e na dissertação de Bianca Guizzo (2005). Ambas as autoras possibilitam argumentar que se desqualifica $O$ comportamento feminino ao associá-lo à fofoca. Sabat (2003) analisa como os filmes infantis atribuem um valor positivo ao silêncio feminino. Em um dos filmes, A pequena sereia, Úrsula (a bruxa do mar) dá conselhos para Ariel (uma sereia) sobre o comportamento feminino considerado adequado para as mulheres que desejam casar - a bruxa canta: "o homem abomina tagarelas/ garota caladinha, ele adora/ se a mulher ficar falando o dia inteiro, fofocando/ o homem se zanga, diz adeus e vai embora..." (apud Sabat, 2003, p.40). Guizzo (2005) analisa situações e falas de crianças e de professores/as no âmbito escolar. Ela comenta uma passagem de seu caderno de anotações sobre a fala de um orientador pedagógico que, dirigindo-se a um menino, classificava "fazer fofoca" como um comportamento próprio de meninas e advertia que tal atitude só envergonharia os homens.

Essas pesquisas reforçam meu argumento de que as PPs mobilizam em suas falas noções do senso comum acerca da masculinidade e da feminilidade, noções que estão implicadas com a construção de significados para meninos e meninas e seus desempenhos escolares. Ao acionar essas noções sem discuti-las, as PPs deixam de considerar os contextos culturais e sociais onde os significados atribuídos a comportamentos de meninas e meninos são produzidos, legitimados e modificados. Sobre essa questão, a pesquisa etnográfica de Claudia Fonseca (2000) em uma comunidade de periferia em Porto Alegre discute, de forma sugestiva, outros significados atribuídos à fofoca, em sua relação com o gênero, naquele contexto cultural - fofoca como força, fofoca 
como sinônimo de respeito, fofoca como marcador de pertencimento social, fofoca para informar e educar, entre outros.

As falas permitem também analisar como as PPs qualificam o comportamento dos meninos. Se, por um lado, elas consideram o comportamento agitado "inadequado" do ponto de vista do comportamento feminino "esperado", por outro lado, suas falas indicam que, quando se trata de meninos, a agitação é qualificada como importante no processo de aprendizagem - "o aluno, para mim, quanto menos limite ele tem, mais ele te exige, mais ele quer. É porque ele está além daquilo ali. Aquilo ali está [...] muito chato".

[Falando sobre o relacionamento com alunos e alunas].

Daniela - Já com as meninas, eu até achava chato, e elas um pouco "cricris", porque elas são todas assim... E os guris não, eles são diretos: "eu quero". Não tem frescuras com eles. [...] Eu entendia mais os meninos. As gurias, eu chegava a achar uma chatice! Eu sempre me identifiquei mais com os meninos do que com as meninas. [...]

Encontro V - 21 de junho de 2004.

É importante retomar, mais uma vez, o argumento sobre o caráter instável e conflitante do processo de significação dos desempenhos. Por um lado, as PPs argumentam que a agitação - tanto dos meninos quanto das meninas - é considerada "inadequada" para o "bom desempenho" escolar. Por outro lado, certa agitação é importante para o "bom desempenho" escolar, porque seria evidência da capacidade do/a aluno/a. Duas noções conflitantes de bom desempenho podem ser visibilizadas aí, uma vez que parecem mobilizar diferentes normas de comportamento: de um lado, a criança organizada, disciplinada, obediente; do outro, a criança ativa, participativa, questionadora, atenta, interessada. Considerando as implicações de gênero na constituição da noção de desempenho escolar, 
poderíamos perguntar quais características têm sido atribuídas a meninos e meninas. Sobre essa questão, Walkerdine (1999a, p.77) argumenta:

\begin{abstract}
Embora a criança [produto das pedagogias psi] seja tomada como neutra, em termos de gênero, de fato ela é sempre pensada como um menino que é ativo, criativo, desobediente, contestador de regras, racional. A figura da menina, por contraste, sugere uma patologia não natural: ela trabalha enquanto o menino é brincalhão, ela segue regras enquanto ele trata de quebrá-las, ela é boa, bem-comportada, não racional. A feminilidade torna-se o Outro da infância racional.
\end{abstract}

Com esse argumento, pode-se pensar que as feminilidades ativa e passiva são classificadas tendo-se como referente a noção de masculinidade ativa, o que contribuiria para reforçar a idéia de que há um princípio normativo masculino (no que se refere a comportamento e a conhecimento) em relação ao qual os desempenhos são classificados e hierarquizados.

Nesse sentido, entendo que discutir como o gênero atravessa e constitui essas normas que permitem às PPs avaliar e hierarquizar os desempenhos possibilita complexificar e problematizar explicações causais de alto/baixo rendimento escolar. Observemos como a PP descreve um menino que não "incomodava":

\footnotetext{
Liane - [...] Eu estava muito preocupada, porque ele não fazia nada, ele não incomodava, mas também não... Incomoda a gente também. [...]
}

Encontro VI - 28 de junho de 2004.

Por um lado, as PPs argumentam que agitação, agressividade, falta de atenção, entre outros, são comportamentos que podem prejudicar o desempenho escolar. Ainda, segundo elas, tais características seriam próprias dos meninos. Mais uma vez, poderíamos nos sentir tentados/as 
a estabelecer uma relação causal: meninos - comportamento agitado baixo desempenho. No entanto, como podemos observar nesses excertos, há meninos que apresentam um baixo desempenho escolar justamente porque são apáticos. Também há meninos que apresentam um comportamento agitado (sem limites), o que, segundo a PP, não afeta seu desempenho. O que poderíamos depreender desses exemplos?

Eles são indicativos do caráter instável e indeterminado dos processos de significação dos desempenhos. Há uma tensão constante que reitera e problematiza as normas fixadas pelas PPs para avaliar os desempenhos. É possível afirmar que nossas práticas pedagógicas estão implicadas na produção de determinados “jeitos de ser" menino e menina, mas também na produção de hierarquias e desigualdades no que se refere ao desempenho escolar.

Foi isso que procurei argumentar neste texto: as diferenças entre meninos e meninas constantemente referidas pelas PPs, ou ainda aquelas apresentadas na reportagem inicial, devem ser entendidas como produtos de um processo de diferenciação que opera lateral e verticalmente, diferenciando meninos de meninas, mas também meninos de meninos e meninas de meninas.

Sensibilizar o olhar para compreender como isso funciona permite tanto visibilizar quanto discutir, analisar e problematizar as relações de poder que constituem, classificam e posicionam meninos e meninas em lugares diferenciados e hierarquizados no que se refere ao desempenho escolar, atribuindo a este último diferentes significados.

\section{REFERÊNCIAS}

BIDDULPH, Steve. Criando meninos. São Paulo: Fundamento, 2002.

COHEN, Michele. 'A habit of healthy idleness': boys' underachievement in historical perspective. In: EPSTEIN, Debbie et al. (Ed.). Failing Boys?: Issues in gender and achievement. Buckingham: Open University Press, 
1998.

COSTA, Marisa Vorraber. Currículo e política cultural. In: COSTA, Marisa Vorraber (Org.). O currículo nos limiares do contemporâneo. 3. ed. Rio de Janeiro: DP\&A, 2001. p. 37-68.

DAL'IGNA, Maria Cláudia. "Há diferença"?: relações entre desempenho escolar e gênero. Porto Alegre: UFRGS, 2005. 167f. Dissertação (Mestrado em Educação) - Programa de Pós-Graduação em Educação, Faculdade de Educação, Universidade Federal do Rio Grande do Sul, Porto Alegre, 2005a.

DAL'IGNA, Maria Cláudia. Desempenho escolar e gênero: um estudo com professoras de séries iniciais. In: REUNIÃO ANUAL DA ASSOCIAÇÃO NACIONAL DE PÓS-GRADUAÇÃO E PESQUISA EM EDUCAÇÃO - ANPEd, 28., 2005, Caxambu/MG. Anais: 40 anos da Pós-Graduação em Educação no Brasil. Microservice Tecnologia Digital da Amazônia Ltda, 2005b. p. 1-15. (Texto completo em CD-rom). DAL'IGNA, Maria Cláudia. Currículo, conhecimento e processos de (in)exclusão na escola. In: LOPES, Maura Corcini; DAL'IGNA, Maria Cláudia (Org.). In/Exclusão nas tramas da escola. Canoas: ULBRA, 2007a. p. $35-48$.

DAL'IGNA, Maria Cláudia. Gênero, sexualidade e desempenho escolar: modos de significar os comportamentos de meninos e meninas. In: REUNIÃO ANUAL DA ASSOCIAÇÃO NACIONAL DE PÓSGRADUAÇÃO E PESQUISA EM EDUCAÇÃO - ANPED, 30., 2007b, Caxambu/MG. Anais. (No prelo).

EPSTEIN, Debbie et al. (Ed.). Failing Boys?: Issues in gender and achievement. Buckingham: Open University Press, 1998.

FONSECA, Claudia. Família, fofoca e honra: etnografia de relações de gênero e violência em grupos populares. Porto Alegre: Ed. da Universidade/UFRGS, 2000.

FOUCAULT, Michel. Verdade e Poder. 18.ed. In: FOUCAULT, Michel. 
Microfísica do poder. Tradução e organização de Roberto Machado. Rio de Janeiro: Graal, 2003. p. 1-14.

GUIZZO, Bianca S. Identidades de gênero e propagandas televisivas: um estudo no contexto da Educação Infantil. Porto Alegre: UFRGS, 2005. $143 f$. Dissertação (Mestrado em Educação) - Programa de Pós-Graduação em Educação, Faculdade de Educação, Universidade Federal do Rio Grande do Sul, Porto Alegre, 2005.

LARROSA, Jorge. Tecnologias do eu e educação. In: Silva, Tomaz Tadeu da (Org.). O sujeito da educação: estudos foucaultianos. 4. ed. Petrópolis: Vozes, 2000. p. 35-86.

MEYER, Dagmar Estermann. Do poder ao gênero: uma articulação teóricoanalítica. In: LOPES, Marta L.; MEYER, Dagmar E.; WALDOW, Vera (Org.). Gênero e saúde. Porto Alegre: Artes Médicas, 1996. p. 41-51.

MEYER, Dagmar Estermann. Gênero e educação: teoria e política. In: LOURO, Guacira; NECKEL, Jane Felipe; GOELLNER, Silvana. Corpo, gênero e sexualidade: um debate contemporâneo. Petrópolis: Vozes, 2003. p. 9-27.

MEYER, Dagmar Estermann. Educação, saúde e politização da maternidade: olhares desde a articulação entre estudos culturais e estudos de gênero. In: SEMINÁRIO BRASILEIRO DE ESTUDOS CULTURAIS EM EDUCAÇÃO: poder, identidade e diferença, 1, 2004, Canoas/RS: ULBRA, 2004. p. 1-17. (Texto completo em CD-ROM).

SABAT, Ruth. Filmes infantis e a produção performativa da heterossexualidade. Porto Alegre: UFRGS, 2003. 183f. Tese (Doutorado em Educação) Programa de Pós-Graduação em Educação, Faculdade de Educação, Universidade Federal do Rio Grande do Sul, Porto Alegre, 2003.

SCOTT, Joan. Gênero: uma categoria útil de análise histórica. Educação \& Realidade, Porto Alegre, v. 20, n. 2, p. 71-99, jul./dez. 1995.

SILVA, Cármen A. D. et al. Meninas bem-comportadas, boas alunas; meninos inteligentes, indisciplinados. Cadernos de Pesquisa, São Paulo, n. 107, p. 207- 
225, jul. 1999.

WALKERDINE, Valerie. O raciocinio em tempos pós-modernos. Educação \& Realidade, Porto Alegre, v. 20, n. 2, p. 207-226, jul./dez. 1995.

WALKERDINE, Valerie. A cultura popular e a erotização das garotinhas. Educação \& Realidade, Porto Alegre, v. 24, n. 2, p. 75-88, jul./dez. 1999a. WALKERDINE, Valerie. Diferença, cognição e educação matemática. Tradução de Gelsa Knijnik. Estudos Leopoldenses: série educação, São Leopoldo, v. 3, n. 4, p. 7-19, jan./jul. 1999b.

WALKERDINE, Valerie. Uma análise foucaultiana da pedagogia construtivista. In: SILVA, Tomaz Tadeu da. Liberdades reguladas: a pedagogia construtivista e outras formas de governo do eu. 2. ed. Petrópolis: Vozes, 1999c. p. 143-216.

ZAKABI, Rosana. Existe outra diferença. Veja, São Paulo, ano 37, n. 23, jun. 2004. p. $72-76$.

Recebimento: 20/07/2007

Aprovação: 19/09/2007

\section{Contato:}

Maria Claudia Dal'Igna

Rua Dona Lida Monteiro, 195

Bairro Teresópolis

Porto Alegre - RS

Cep: $91720-300$

mcdaligna@hotmail.com 